\title{
Temporal and Spatial Variation Characteristics of NDVI and Its Relationship with Environmental Factors in Huangshui River Basin from 2000 to 2018
}

\author{
Jianming Feng',2, Biqiong Dong², Tianling Qin ${ }^{2 *}$, Shanshan Liu², \\ Junwei Zhang ${ }^{2,3}$, Xinfeng Gong ${ }^{2,4}$ \\ ${ }^{1}$ College of Resource Evironment and Tourism, Capital Normal University, Beijing 100048, China \\ ${ }^{2}$ State Key Laboratory of Simulation and Regulation of Water Cycle in River Basin, China Institute of Water Resources \\ and Hydropower Research, Beijing, 100038, China \\ ${ }^{3}$ College of Hydraulic \& Environmental Engineering, China Three Gorges University, Yichang 443002, China \\ ${ }^{4}$ College of Conservancy Engineering, Zhengzhou University, Zhengzhou 450000, China
}

Received: 20 September 2020

Accepted: 16 November 2020

\begin{abstract}
Climate change, topographical evolution and human activities are the main driving factors of NDVI spatiotemporal evolution. Quantitative identification of the driving mechanism can provide support for water conservation, artificial forest construction and soil erosion control. Taking Huangshui River Basin as an example, accumulated temperature, accumulated precipitation and NDVI of 16-days from 2000 to 2018 were collected and manipulated based on slope trend analysis, correlation analysis and other methods to identify the spatial and temporal distribution characteristics of NDVI in this study. The impact mechanisms of climate factors, topography and land use on spatial and temporal distribution characteristics of NDVI were quantitatively analyzed as well. The results show that: (1) the annual average growth rate of NDVI in Huangshui River Basin from 2000 to 2018 is $0.28 \% / \mathrm{a}$. NDVI in spring, summer and autumn also showed an increasing trend. The increasing area accounts for $38.04 \%$ of the whole basin, which was mainly distributed in the middle and lower reaches and northwest of Huangshui River Basin. (2) NDVI was positively correlated with accumulated temperature, accumulated precipitation and effective accumulated precipitation of 16 days, and the areas with (extreme) significant positive correlation accounted for $77.89 \%, 86.52 \%$ and $86.18 \%$ of the whole basin respectively. However, the correlation between NDVI and 16-days accumulated temperature increased first and then decreased from southeast to northwest in Huangshui River Basin. While the correlation between NDVI and accumulated precipitation (or effective accumulated precipitation) gradually increased from southeast to northwest. (3) NDVI is affected not only by altitude and aspect, but also by surface conditions
\end{abstract}

*e-mail: qintl@iwhr.com 
and human factors. The areas with high NDVI are mainly distributed above $2700 \mathrm{~m}$ above sea level. Compared with other slope aspect, NDVI on the semi-shady slope is higher, the growth rates of NDVI on semi-sunny slope and shady slope are the fastest, and the growth rate on sunny slope is the slowest. The growth of NDVI on shady slope in spring and autumn is the fastest, that on semi-sunny slope in summer is the fastest, and that on sunny slope in autumn, spring and summer is the slowest. (4) The annual average growth rate of NDVI in arable land, woodland, grassland, water area and unused land are $0.36 \%, 0.27 \%, 0.28 \%, 0.24 \%$ and $0.17 \%$ respectively. The annual average decrease rate of NDVI in urban land use is $0.13 \%$. Large area increase of plantation forest is an important factor for increase of NDVI.

Keywords: NDVI, spatiotemporal variation, climatic factors, topographic features, land use

\section{Introduction}

As an important component of global terrestrial ecosystem, vegetation plays an important role in global material and energy cycle, carbon balance regulation and climate stability [1]. With the rapid development of remote sensing technology and long-term accumulation of remote sensing data, the correlation between NDVI and biomass or dynamics of vegetation has been well revealed $[2,3]$. The study on spatiotemporal changes of NDVI is helpful to uncover the spatiotemporal evolution characteristics of vegetation from the side. The biomass of vegetation was significantly affected by climate change. The increase of precipitation and temperature can promote the formation of spatial heterogeneity pattern of forest dynamics [4], as well as influence the spatiotemporal variation of NDVI [5]. The impact of climate change on NDVI is often complex rather than direct. For example, the influence of temperature and precipitation on NDVI usually depends on the characteristics of biological communities [6-8]. The response of vegetation to climatic factors varies in different seasons. Precipitation is the main climatic factor which affects the growth of vegetation in summer and growing season $[9,10]$. The impact of precipitation on vegetation is related to vegetation types [11-13]. NDVI is also significantly affected by human activities $[14,15]$. The increase of plantation area has a prominent effect on NDVI [16, 17]. Meanwhile, influenced by topography, water content may be an important limiting factor for vegetation in growth season in inland mountainous areas [18, 19]. Mountain ecosystem has complex terrain and climate characteristics, which is likely to be strongly affected by climate change [20]. Therefore, the spatiotemporal changes of NDVI are influenced by both natural and anthropogenic factors [21]. Natural factors mainly include air temperature [22], precipitation [11], topography and altitude [20], while anthropogenic factors mainly include land use types [23].

At present, global climate change has had a significant impact on terrestrial ecosystems. In this context, analyzing the temporal and spatial variation characteristics of NDVI and its relationship with environmental factors is of great significance for artificial forest construction, soil erosion control, water conservation and maintenance of regional ecological diversity [24]. However, previous studies mostly analyzed the impact of several natural or anthropogenic factors on NDVI on the monthly scale with less comprehensive consideration of the impacts of multiple natural factors and human factors on the spatiotemporal changes of NDVI.

In the past 20 years, vegetation growth has increased distinctly in most parts of China [25] owing to the role of green programme and other large-scale eco-construction projects in controlling ecological degradation [14, 26, 27]. Huangshui River Basin is located in the transition zone between Qinghai Tibet Plateau and Loess Plateau. As a sensitive area to climate change and human activities, the ecosystem is relatively fragile, and vegetation change has always been the focus of people's attention $[28,29]$. In this study, NDVI, climate data, DEM and land use data from 2000 to 2018 were collected to investigate the temporal and spatial evolution characteristics of NDVI. In the time scale of 16 days, the influence relationship between NDVI and 16-days accumulated temperature, cumulative precipitation, effective cumulative precipitation, topography and landform and land use change was further clarified, which provided strong support for soil erosion control and ecological barrier construction in the Slope of Huangshui River Basin.

\section{Material and Methods}

\section{Study Area}

Huangshui River is a first-degree tributary of the Yellow River, which flows through Qinghai and Gansu provinces. The main stream has a total length of $374 \mathrm{~km}$ with drainage area of $17733 \mathrm{~km}^{2}$. The study site covered most of the Huangshui River basin from the upper reaches of Minhe County, with a main stream length of $278 \mathrm{~km}$ and a drainage area of $15,558 \mathrm{~km}^{2}$. The study area ranges from $36^{\circ} 02^{\prime} \mathrm{N}-37^{\circ} 28^{\prime} \mathrm{N}$ and $100^{\circ} 42^{\prime} \mathrm{E}-103^{\circ} 01^{\prime} \mathrm{E}$, which has the plateau arid and semi-arid continental climate (Fig. 1). From 1960 to 2017, the annual average precipitation was $381.1 \mathrm{~mm}$, 


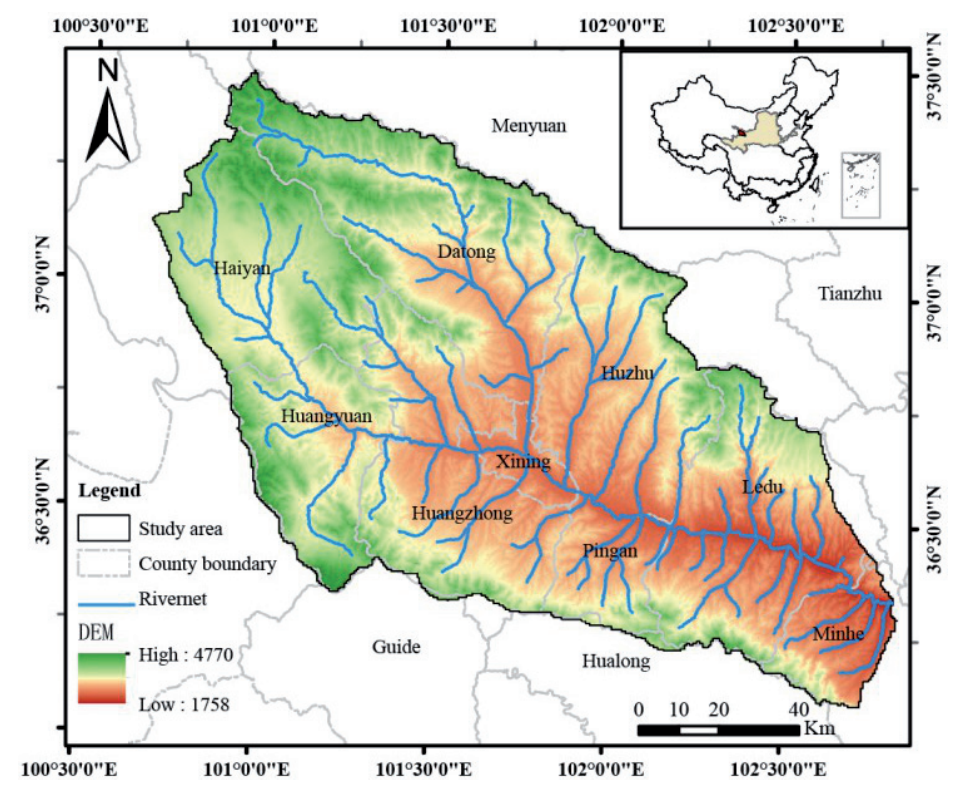

Fig. 1. Location and DEM of the Huangshui River basin.

and the annual average temperature ranged from $3.1^{\circ} \mathrm{C}$ to $7.9^{\circ} \mathrm{C}[29] .76 .1 \%$ of the study area has NDVI values higher than 0.6. Since the $1970 \mathrm{~s}$, a large number of artificial forest construction projects have been carried out in Huangshui River Basin, such as the Yellow River water and soil conservation ecological project and comprehensive management of soil and water conservation. By 2017, the forest area accounted for $38.36 \%$ of the basin area [28].

\section{Data Sources and Processing}

The basic data needed in this study mainly include MOD13Q1-NDVI data, meteorological data, land use data and DEM data. MODIS-NDVI data is the product of NASA's earth observation system with spatial resolution of $250 \mathrm{~m} \times 250 \mathrm{~m}$ and the time resolution of $16 \mathrm{~d}$. The time span of MODIS-NDVI is from 2000 to 2018. The data set is of high quality and can be used to deal with water, cloud and heavy aerosols. It is widely used in NDVI related research. The NDVI time series data set is obtained by preprocessing MODIS data format and projection transformation by MRT. Meteorological data derived from China Meteorological Data Service Center. Daily temperature and precipitation of 6 weather stations in Huangshui region and its surrounding areas from 2000 to 2018 are selected. The accumulated temperature $\left(>=10^{\circ} \mathrm{C}\right)$, accumulated precipitation and effective precipitation of every 16 days are interpolated by IDW tool of ArcGIS 10.5 platform. The obtained grid data has the same spatial resolution as NDVI. DEM data are from National Geomatics Center of China with a spatial resolution of $30 \times 30 \mathrm{~m}$, which can be divided into four types: semi-shady slope $\left(45^{\circ}-135^{\circ}\right)$, sunny slope $\left(135^{\circ}-225^{\circ}\right)$, semi-sunny slope $\left(225^{\circ}-315^{\circ}\right)$ and shady slope $\left(315^{\circ}-45^{\circ}\right)$. The land use data of 1980,2000 and 2005 are also from National Geomatics Center of China, and the data of 2017 are from the Department of Natural Resources of Qinghai Province. Through arcgis 10.5 , land use is divided into six types: cultivated land, woodland, grassland, water area, urban land and unused land.

\section{Methods}

This paper analyzes the temporal and spatial variation of NDVI and its relationship with environmental factors in Huangshui River Basin. Firstly, the temporal and spatial variation characteristics of NDVI were analyzed by correlation analysis and slope trend analysis to clarify the variation characteristics of NDVI sequence in interannual, seasonal and 16 days. On this basis, the relationship between NDVI and environmental factors was analyzed. The accumulated temperature, accumulated precipitation and effective accumulated precipitation of every 16 days are taken as the key factors to analyze the impact of climate factors on the spatial and temporal variation of NDVI at the interannual and seasonal scales. This paper also analyzed the impacts of terrain, geomorphic factors and land use factors on the spatial and temporal changes of NDVI according to the results of terrain area, aspect, land use types and landscape pattern changes respectively (Fig. 2).

\section{Trend Analysis}

Slope trend analysis method refers to analysis of temporal change trend and intensity of vegetation index by the unary linear regression analysis method, which can reflect the spatial distribution characteristics of temporal change trend of NDVI [8, 12, 30]. 


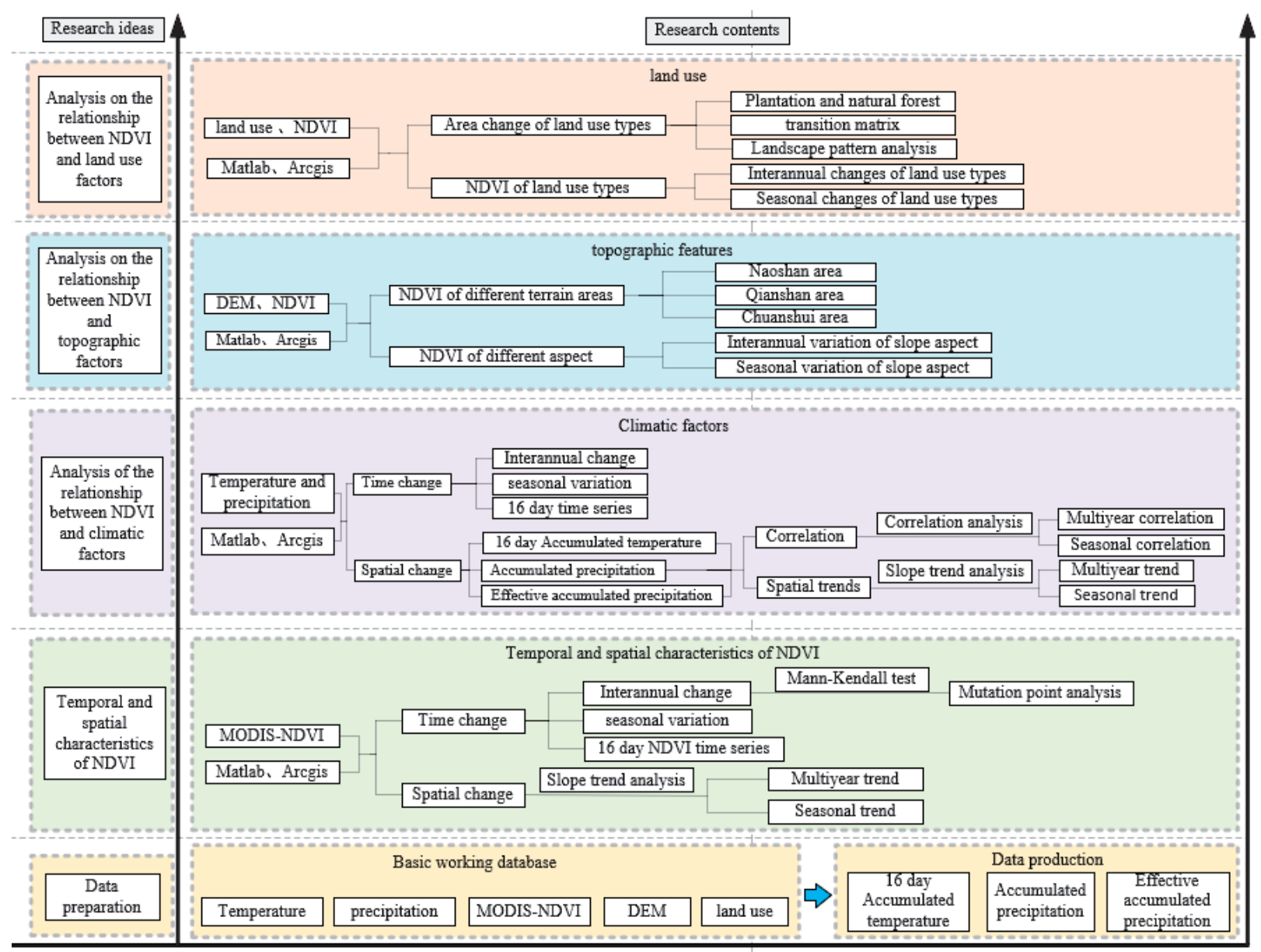

Fig. 2. Technology Roadmap.

The significance level of these variables was evaluated by F-test. To assess the extent of temporal change of NDVI or other variables, we divided it into five levels (Table 1).

\section{Effective Precipitation}

At the pixel scale, correlation analysis method is used to study the response relationship between NDVI and accumulated temperature, accumulated precipitation and effective accumulated precipitation of every 16 days from 2000 to 2018. Then the response relationship at the pixel scale is accumulated to the basin scale to analyze the correlation [23, 31, 32]. In order to evaluate the correlation between NDVI and temperature and precipitation, we divided it into eight grades (Table 2).
The effective precipitation can be calculated by formula [33]:

$$
\mathrm{EP}=\sum_{i=1}^{\mathrm{n}} \mathrm{UP}_{i}
$$

...where, $\mathrm{P}_{\mathrm{i}}$ is the monthly precipitation and $\mathrm{U}$ represents the effective utilization coefficient of precipitation [34]. Different monthly precipitation corresponds to different $\mu$ values (Table 3 ).

\section{Landscape Pattern Analysis}

Fragstats4.2 was used to calculate Class area (CA), Edge density (ED), Number of patches (NP), Largest patch index (LPI) and Mean patch size (MPS)

Table 1. Change trend classification table.

\begin{tabular}{|c|c|c|c|c|c|}
\hline Trends & Slope & Significance & Trends & Slope & Significance \\
\hline Extremely significant decrease & $<0$ & $\mathrm{p}<0.01$ & Extremely significant increase & $>0$ & $\mathrm{p}<0.01$ \\
\hline Significant decrease & $<0$ & $0.01<\mathrm{p}<0.05$ & Significant increase & $>0$ & $0.01<\mathrm{p}<0.05$ \\
\hline No significant change & $<0$ & $\mathrm{p}>0.05$ & No significant change & $>0$ & $\mathrm{p}>0.05$ \\
\hline
\end{tabular}


Table 2. Correlation classification table.

\begin{tabular}{|c|c|c|c|}
\hline Relevance & Range & Relevance & Range \\
\hline Extremely significant negative correlation & $-1<\mathrm{R}<-0.7$ & Extremely significant positive correlation & $0.7<\mathrm{R}<1$ \\
\hline Significantly negative correlation & $-0.7<\mathrm{R}<-0.5$ & Significantly positive correlation & $0.5<\mathrm{R}<0.7$ \\
\hline Low degree negative correlation & $-0.5<\mathrm{R}<-0.3$ & Low degree positive correlation & $0.3<\mathrm{R}<0.5$ \\
\hline Weak negative correlation & $-0.3<\mathrm{R}<0$ & Weak positive correlation & $0<\mathrm{R}<0.3$ \\
\hline
\end{tabular}

Note: $\mathrm{R}$ is the correlation coefficient

Table 3. The effective utilization coefficient of precipitation.

\begin{tabular}{|c|c|c|c|c|c|c|}
\hline Monthly precipitation/mm & $<5$ & $5 \sim 30$ & $30 \sim 50$ & $50 \sim 100$ & $100 \sim 150$ & $150 \sim 200$ \\
\hline $\mathrm{U}$ & 0 & 0.85 & 0.80 & 0.75 & 0.65 & 0.55 \\
\hline
\end{tabular}

Note: when the monthly precipitation is greater than $200 \mathrm{~mm}$, it is calculated as $200 \mathrm{~mm}$.

and to overlay the land use data of 2000 and 2005 in 2017. Arcgis10.5 was used to overlay land use data of 2000,2005 and 2017 to obtain land use type transfer matrixes of 2000-2005 and 2005-2017. The degree of fragmentation, complexity and irregularity of landscape, and the impact of human activities on landscape pattern were analyzed [35].

\section{Results}

\section{Temporal and Spatial Characteristics}

\section{Time Change}

From 2000 to 2018, the spatial mean of annual NDVI in Huangshui River Basin ranged from 0.297 to 0.351 , with an average annual increase of $0.28 \%$ (Fig. 3a). The spatial mean of NDVI in spring, summer and autumn of each year increased by $0.46 \%, 0.54 \%$ and $0.58 \%$ per year respectively (Fig. $3 b$ ). The spatial mean of NDVI in summer of each year was the largest, followed by spring and autumn (Fig. 3b). The 16-days NDVI time series showed an upward trend, ranging from 0.021 to 0.681 . The increasing trend of NDVI was the fastest in spring, and the decreasing trend of that was the fastest in autumn, while in summer the NDVI changed smoothly (Fig. 3c).

\section{Spatial Change}

From 2000 to 2018, the areas with annual average NDVI less than 0.3 were mainly distributed in the middle and lower reaches of Huangshui basin, the north and south of Haiyan and the middle of Huangyuan (Fig. 4a). The area showing an increasing trend of annual NDVI accounted for $38.04 \%$ of the river basin, which was mainly distributed in the areas with low NDVI. The area with a decreasing trend of that
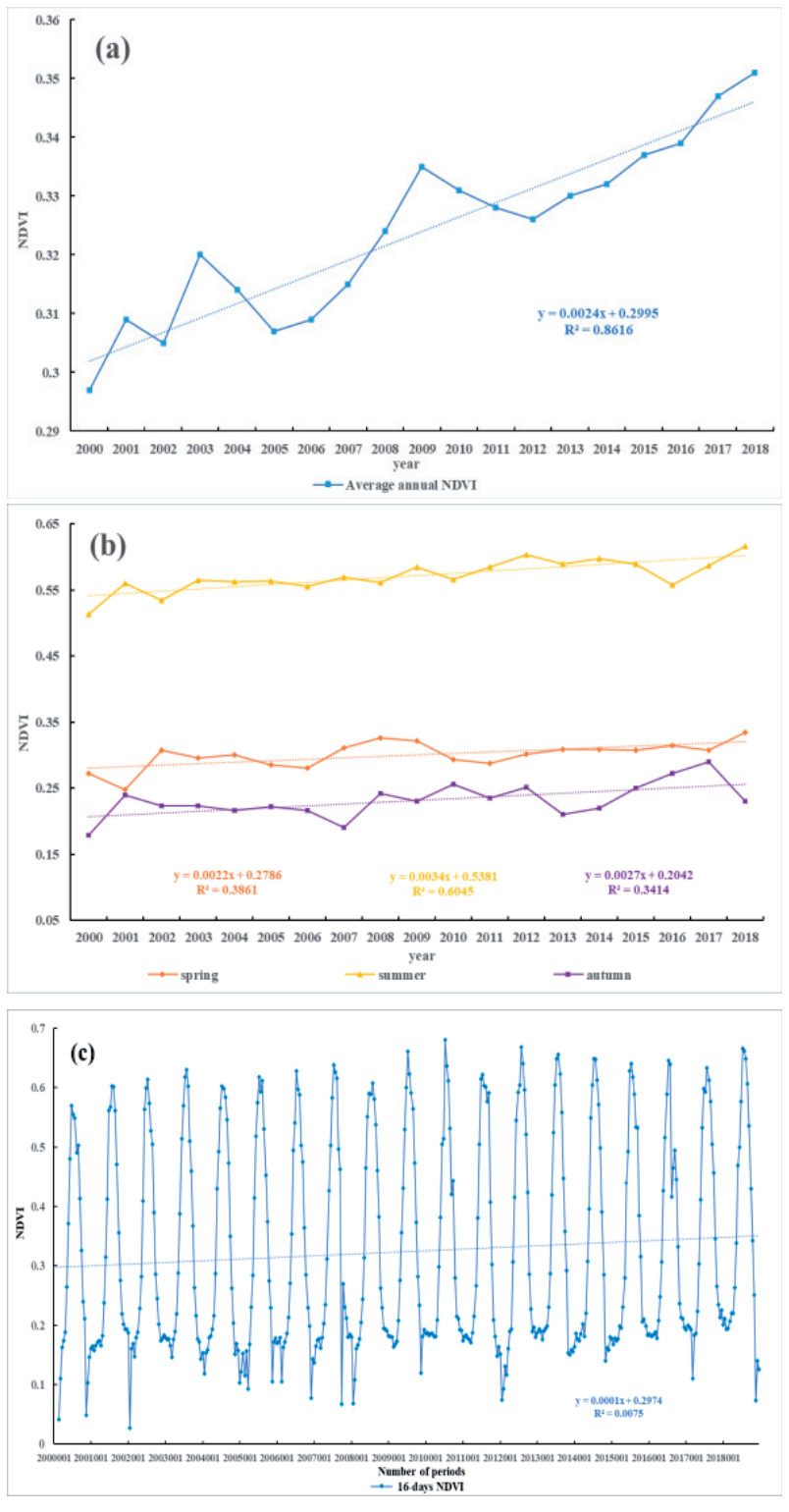

Fig. 3. The temporal change trend of spatial mean of annual a), seasonal b), 16-days NDVI c) from 2000 to 2018 respectively. 

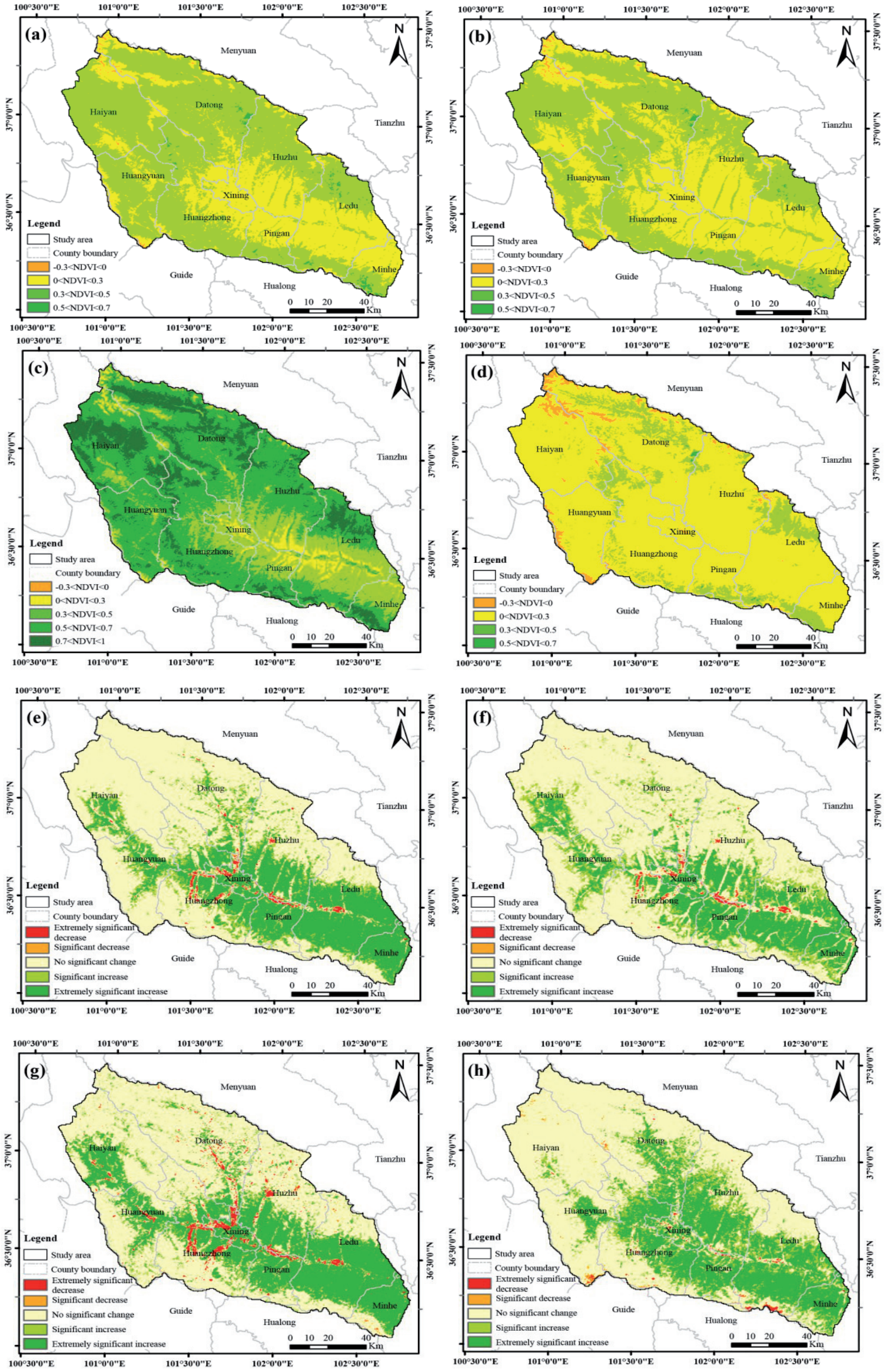

Fig. 4. Annual average NDVI in Huangshui River Basin a), in spring b), summer c) and autumn d). The spatial distribution of temporal change trends of NDVI annually e) and seasonally in spring f), summer g) and autumn h) from 2000 to 2018. 
Table 4. Statistical table of temporal change trends of NDVI annually and seasonally in Huangshui River Basin (\%).

\begin{tabular}{|c|c|c|c|c|}
\hline Trends & Year & Spring & Summer & Autumn \\
\hline Extremely significant decrease & 0.95 & 0.74 & 2.07 & 0.45 \\
\hline Significant decrease & 0.30 & 0.45 & 0.80 & 0.72 \\
\hline No significant change & 60.71 & 66.14 & 58.59 & 59.60 \\
\hline Significant increase & 8.03 & 10.72 & 6.11 & 9.99 \\
\hline Extremely significant increase & 30.01 & 21.95 & 32.43 & 29.24 \\
\hline
\end{tabular}

accounted for $1.25 \%$, which was mainly distributed in the middle valley of Huangshui River Basin (Table 4, Fig. 4 e). The areas with annual average NDVI in summer greater than 0.3 accounted for $95.41 \%$, while those in spring and autumn were relatively low (Fig. $4 \mathrm{~b}$-d). The areas with an increasing trend of annual NDVI in spring, summer and autumn accounted for $32.67 \%, 38.54 \%$ and $39.23 \%$ of the river basin respectively, which were mainly distributed in the middle and lower reaches and northwest of Huangshui River Basin. The areas showing a decreasing trend of those accounted for $1.19 \%, 2.87 \%$ and $1.17 \%$ respectively, which were mainly distributed in the Central Valley of Huangshui River Basin (Table 4; Fig. 4 f-h).

\section{Impact Factors}

\section{Climatic Factors}

From 2000 to 2018, the area which showed significant or extremely significant positive correlation between NDVI and 16-days accumulated temperature in Huangshui River Basin accounted for $77.89 \%$ of the river basin. The area with low correlation between the two was mainly distributed in the middle and lower reaches of Huangshui River Basin, and the area showing an increasing trend of this correlation accounted for $81.11 \%$ of the basin (Table 5, 6; Fig 5 a, e). Spring NDVI and 16-days accumulated temperature mainly showed an extremely significant positive correlation and extremely significant increasing trend of the correlation (Table 5, 6; Fig. 5 b, f). The area with negative correlation between NDVI in summer and 16-days accumulated temperature accounted for 19.3\% of the basin. The area showing a decreasing trend of this correlation accounted for $12.42 \%$ of the basin, which were mainly distributed in the middle and lower reaches of Huangshui River Basin and Northwest China (Table 5, 6; Fig. 5 c, g). The correlation between NDVI and 16-days accumulated temperature in autumn was poor, but the area showing an increasing trend of correlation accounted for $62.91 \%$, which was mainly distributed in the northwest of Huangshui River Basin

Table 5. Statistical table of correlation between NDVI and 16DAT annually and seasonally in Huangshui River Basin (\%).

\begin{tabular}{|c|c|c|c|c|}
\hline Relevance & Year & Spring & Summer & Autumn \\
\hline Low degree negative correlation & 0 & 0 & 6.21 & 0 \\
\hline Weak negative correlation & 0 & 0.05 & 13.09 & 0.95 \\
\hline Weak positive correlation & 1.44 & 0.73 & 37.66 & 87.06 \\
\hline Low degree positive correlation & 20.67 & 4.17 & 28.49 & 11.89 \\
\hline Significant positive correlation & 75.88 & 24.19 & 13.59 & 0.1 \\
\hline Extremely significant positive correlation & 2.01 & 70.86 & 0.96 & 0 \\
\hline
\end{tabular}

Table 6. Statistical table of spatial change trend of correlation between NDVI and temperature in Huangshui River Basin (\%).

\begin{tabular}{|c|c|c|c|c|c|c|c|}
\hline Correlation change trends & 16DAT & Spring & Summer & Autumn & AVT & MVT & MMDT \\
\hline Extremely significant decrease & 0 & 0 & 9.77 & 0 & 0 & 0 & 0 \\
\hline Significant decrease & 0 & 0 & 2.65 & 0 & 0 & 0 & 0 \\
\hline No significant change & 18.89 & 0.23 & 23.67 & 37.09 & 18.87 & 16.96 & 24.14 \\
\hline Significant increase & 71.77 & 0.17 & 9.82 & 25.44 & 70.58 & 62.22 & 69.29 \\
\hline Extremely significant increase & 9.34 & 99.60 & 54.08 & 37.47 & 10.55 & 20.82 & 6.57 \\
\hline
\end{tabular}


(Table 5, 6; Fig. 5 d, h). The spatial change trend of correlation between NDVI and the average value of 16-days temperature (AVT), the maximum value of 16-days temperature (MVT) or the maximum and minimum difference of 16-days temperature (MMDT) are basically the same as that between annual NDVI and 16-days accumulated temperature (16DAT), which first increases and then decreases from southeast to northwest, but the correlation between NDVI and the maximum value of 16-days temperature shows a very significant increase trend, and the trend is obviously higher (Table 6; Fig. 5 i-k).

From 2000 to 2018, 86.52\% of the Huangshui River Basin manifested a significant or extremely significant positive correlation between NDVI and accumulated precipitation of 16 days (AP), and $79.34 \%$ of the area showed an increasing trend of correlation (Table 7, 8; Fig.6a, e). In spring, NDVI was mainly positively correlated with 16 days accumulated precipitation in low degree. The areas with significant positive
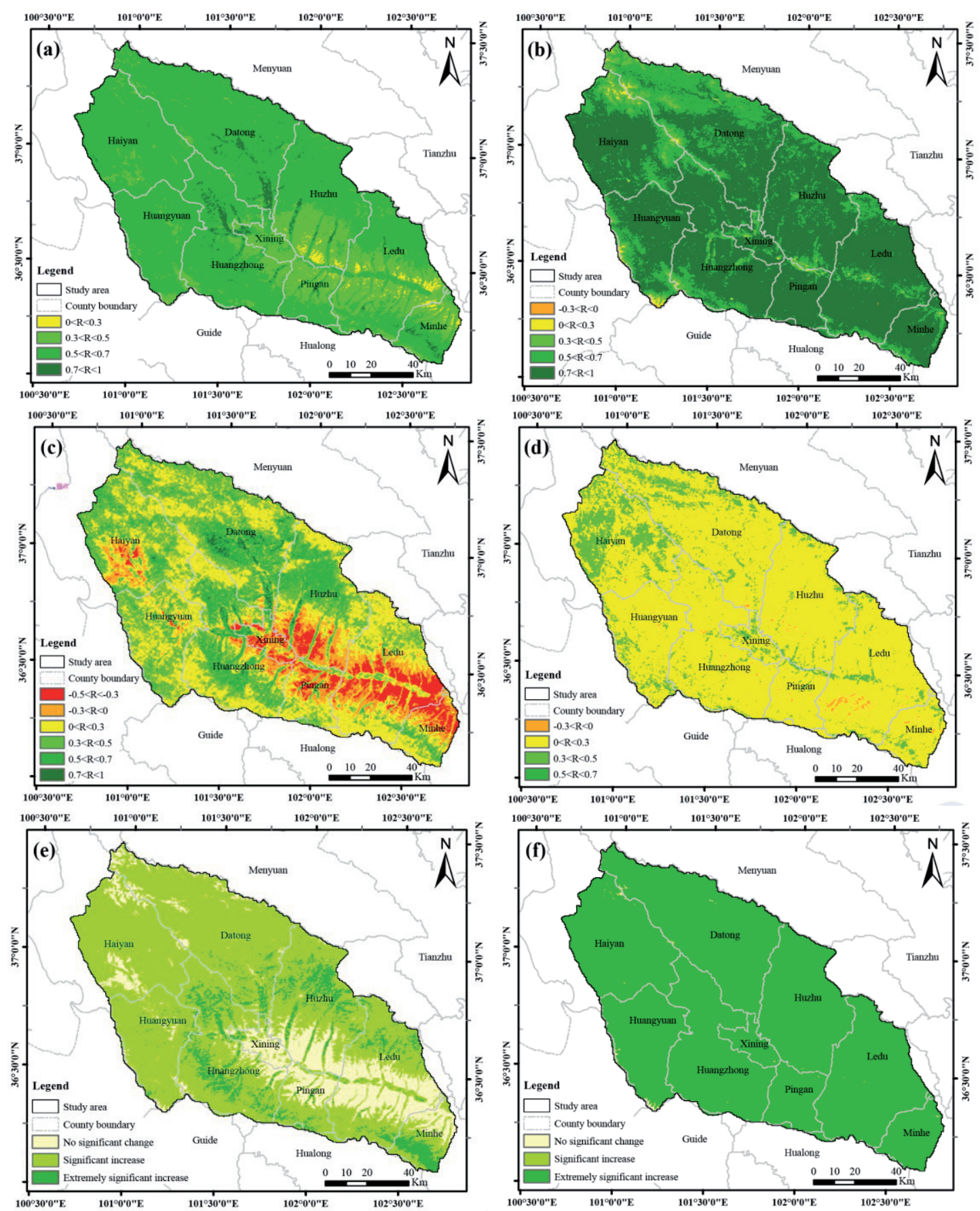

Fig. 5. Spatial distribution map of correlation between annual a), spring b), summer c), autumn d) NDVI and 16-days accumulated temperature from 2000 to 2018; The spatial distribution of temporal change trend of correlation between annual NDVI e), spring NDVI f), summer NDVI g), autumn NDVI h) and 16DAT, and between annual NDVI and AVT i), MVT j) or MMDT k). 

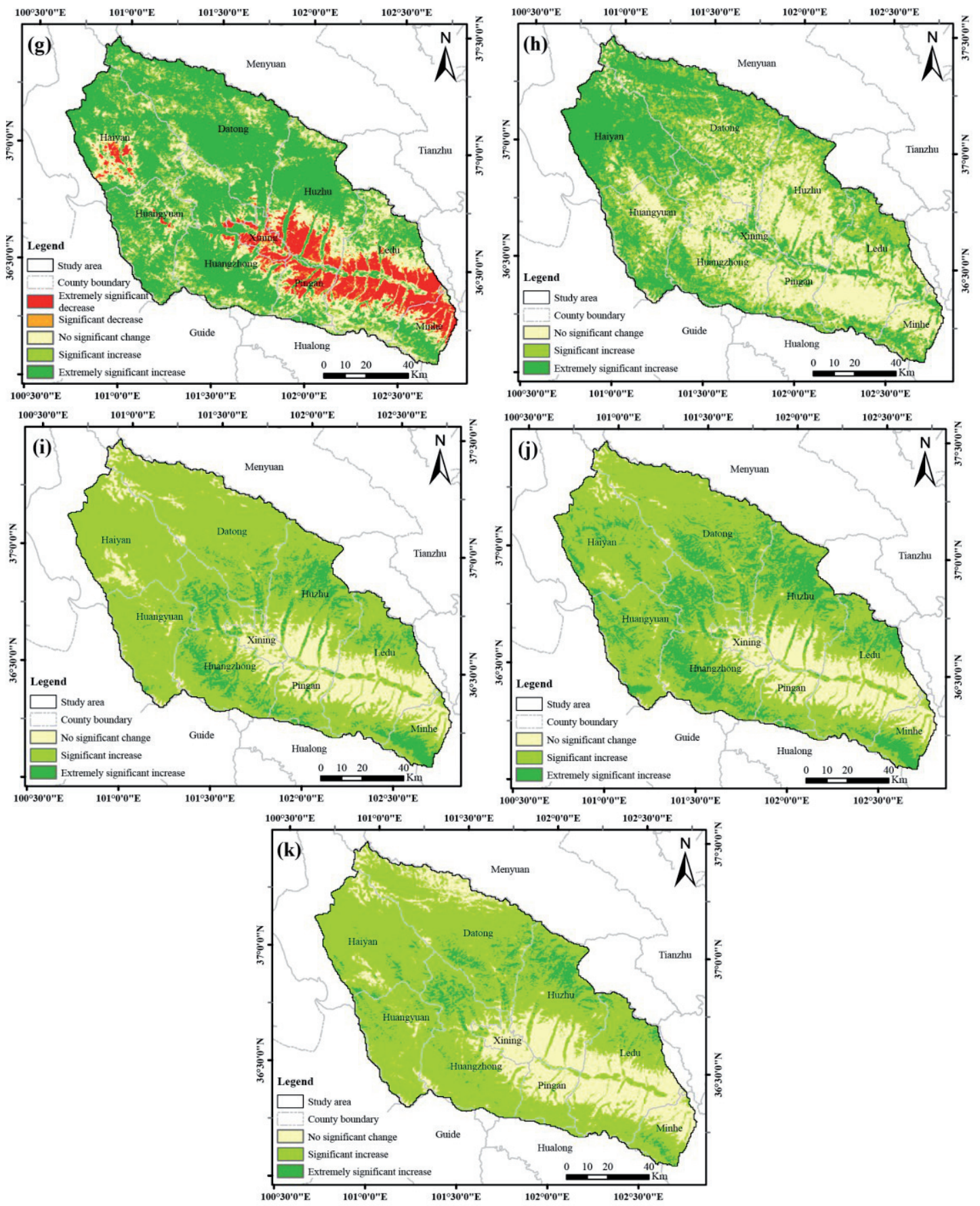

Fig. 5. Continued.

correlation between the two were mainly distributed in Ledu and Minhe, but the area with increasing trend of correlation accounted for $99.18 \%$ (Table 7, 8; Fig. 6 b, f). In summer, the area of weak correlation between NDVI and accumulated precipitation of 16 days was mainly distributed in the middle and lower reaches of Huangshui River Basin and the south of Haiyan. The area with a decreasing trend of correlation accounted for $3.41 \%$, which was mainly distributed in the lower reaches of Huangshui River Basin (Table 7, 8; Fig. 6 c, g). The correlation between NDVI in autumn and accumulated precipitation was poor, but the area with increasing trend of correlation accounted for $79.47 \%$ (Table 7, 8; Fig. $6 \mathrm{~d}, \mathrm{~h}$ ). The spatial change trend of correlation between NDVI and the average value of 16-days precipitation (AVP), the maximum value of 16-days precipitation (MVP) or the maximum and minimum difference of 16-days precipitation (MMDP) are basically the same as that between NDVI and 16-days cumulative precipitation (AP). The correlation is gradually increasing from southeast to northwest (Table 8; Fig. 6 i-k).

In the period from 2000 to $2018,86.18 \%$ of the Huangshui River Basin showed a significant or 
extremely significant positive correlation between NDVI and effective accumulated precipitation. $79.23 \%$ of the basin manifested an increasing trend of the correlation (Table 9, 10; Fig. 7 a, e). NDVI in spring was mainly positively correlated with effective accumulated precipitation in low degree, while the area with significant positive correlation between the two was distributed in Ledu and Minhe. The area with an increasing trend of correlation accounted for $99.14 \%$ Table 9, 10; Fig. 7 b, f). The area with weak correlation between NDVI in summer and effective accumulated precipitation was mainly distributed in the middle and lower reaches of Huangshui River Basin and the south of Haiyan. The area with a decreasing trend of correlation accounted for $3.41 \%$, which was mainly distributed in the lower reaches of Huangshui River Basin (Table 9, 10; Fig. 7 c, g). The correlation between NDVI and effective accumulated precipitation in autumn was poor, but the area with increasing trend of correlation accounted for $81.02 \%$ (Table 9, 10; Fig. 7 d, h). The spatial change trend of correlation between NDVI and the average
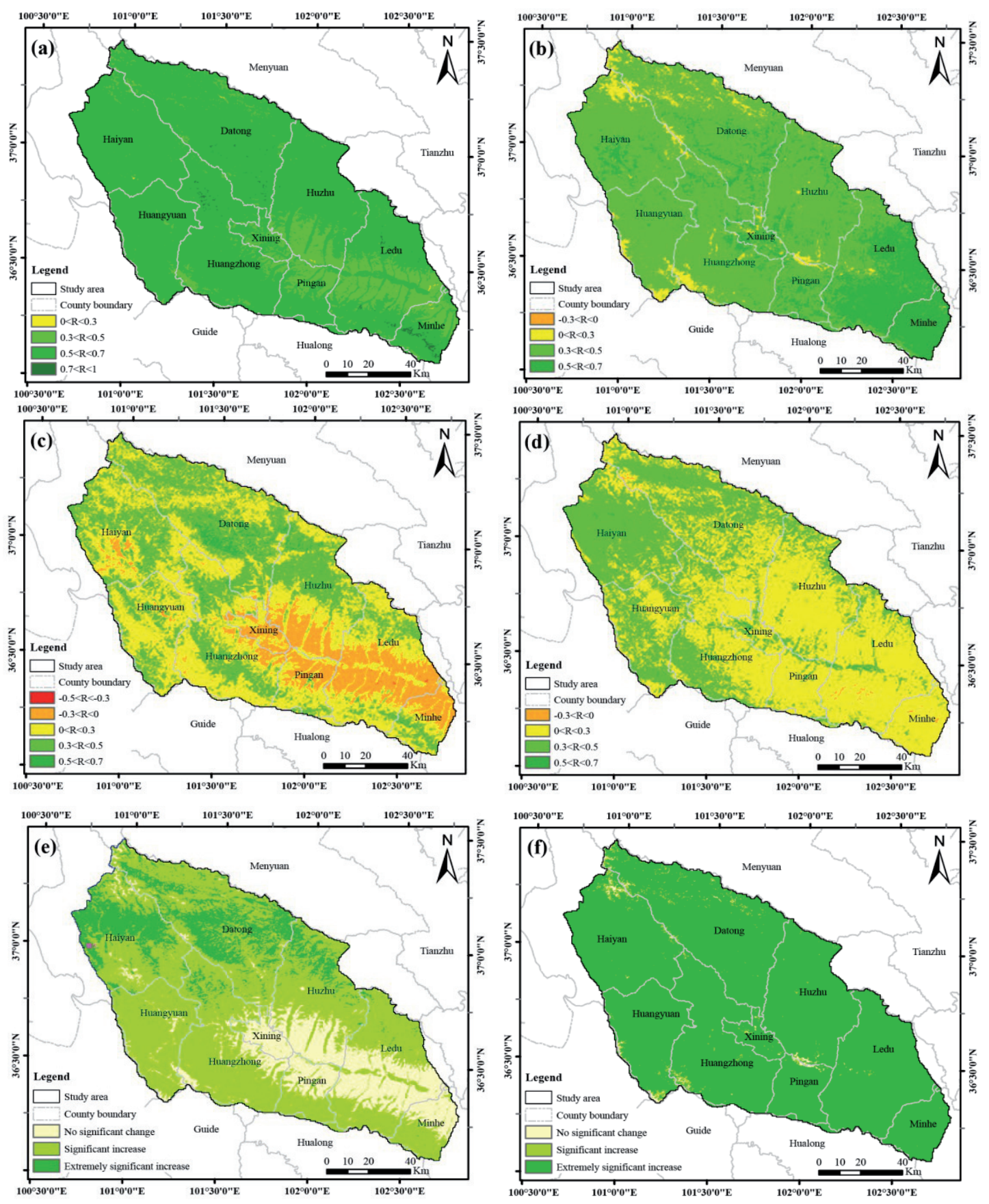

Fig. 6. Spatial distribution map of correlation between annual a), spring b), summer c), autumn d) NDVI and accumulated precipitation from 2000 to 2018; The spatial distribution of temporal change trend of correlation between NDVI and AP e), spring f), summer g), autumn h), AVP i), MVP j) or MMDP k). 

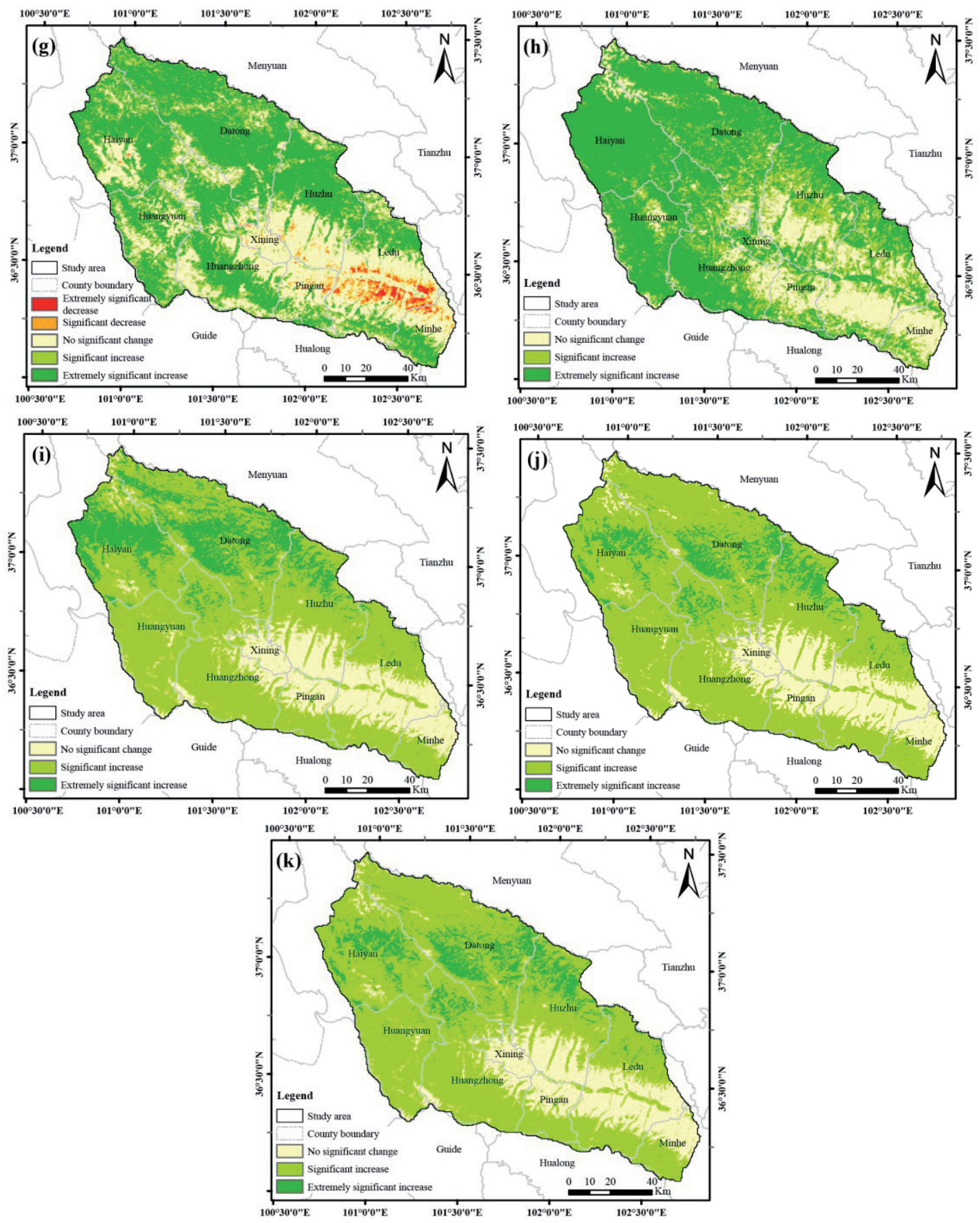

Fig. 6. Continued.

value of 16-days effective precipitation (AVEP), the maximum value of 16-days effective precipitation (MVEP) or the maximum and minimum difference of 16-days effective precipitation (MMDEP) are basically the same as that between NDVI and effective accumulated precipitation (EAP). The correlation is gradually increasing from southeast to northwest (Table 10; Fig. 7 i-k).

\section{Topographic Features}

According to the characteristics of topography, climate, soil, vegetation and agricultural production,
Huangshui River Basin is divided into three geomorphic units: Naoshan area (above $2700 \mathrm{~m}$ ), Qianshan area (between $2200 \mathrm{~m}-2700 \mathrm{~m}$ ) and Chuanshui area (below $2200 \mathrm{~m}$ ). The areas with NDVI larger than 0.3 account for $80.13 \%, 28.08 \%$ and $11.21 \%$ of the basin in Naoshan area, Qianshan area and Chuanshui area respectively. The areas with high NDVI are mainly distributed above the altitude of $2700 \mathrm{~m}$ (Table 11). The areas with NDVI larger than 0.3 accounted for $16.04 \%, 15.19 \%, 14.82 \%$ and $17.95 \%$ on sunny slope, semi sunny slope, shady slope and semi shady slope respectively. In general, NDVI of semi-shady slope was greater than NDVI of sunny slope, followed by NDVI of semi-sunny slope 
and NDVI of shady slope (Table 12). The average growth rates of NDVI on sunny, semi-sunny, shady and semi-shady slopes were $0.26 \%, 0.3 \%, 0.3 \%$ and $0.28 \%$ respectively. The growth rate of NDVI on semi-sunny and shady slopes were the fastest and that of sunny slopes was the slowest (Fig. 8a). In spring and autumn, the NDVI of shady slope increased fastest, with an average growth rate of $0.47 \%$ and $0.61 \%$ respectively. In summer, NDVI of semi-sunny slope increased fastest with an average growth rate of $0.57 \%$. In spring, summer and autumn, the growth rate of NDVI on sunny slope was the slowest, with an average growth rate of $0.44 \%, 0.49 \%$ and $0.55 \%$ respectively (Fig. 8 b-e).

\section{Land Use}

The arable land, grassland and urban land are mainly distributed in the middle and lower reaches of

Table 7. Statistical table of correlation between NDVI and AP in Huangshui River Basin (\%).

\begin{tabular}{|c|c|c|c|c|}
\hline Relevance & Year & Spring & Summer & Autumn \\
\hline Weak negative correlation & 0 & 0.02 & 15.98 & 0.65 \\
\hline Weak positive correlation & 0.05 & 5.61 & 48.84 & 61.74 \\
\hline Low degree positive correlation & 13.43 & 71.88 & 33.63 & 37.33 \\
\hline Significant positive correlation & 86.17 & 22.49 & 1.55 & 0.28 \\
\hline Extremely significant positive correlation & 0.35 & 0 & 0 & 0 \\
\hline
\end{tabular}

Table 8. Statistical table of spatial distribution of temporal change trend of correlation between NDVI and precipitation in Huangshui River Basin (\%).

\begin{tabular}{|c|c|c|c|c|c|c|c|}
\hline Correlation change trends & AP & Spring & Summer & Autumn & AVP & MVP & MMDP \\
\hline Extremely significant decrease & 0 & 0 & 0.73 & 0 & 0 & 0 & 0 \\
\hline Significant decrease & 0 & 0 & 2.68 & 0 & 0 & 0 & 0 \\
\hline No significant change & 20.66 & 0.82 & 34.43 & 22.83 & 20.68 & 20.44 & 20.53 \\
\hline Significant increase & 63.54 & 1.45 & 12.12 & 17.12 & 63.10 & 69.80 & 69.10 \\
\hline Extremely significant increase & 15.8 & 97.73 & 50.04 & 60.05 & 16.22 & 9.76 & 10.37 \\
\hline
\end{tabular}

Table 9. Statistical table of correlation between NDVI and EAP in Huangshui River Basin (\%).

\begin{tabular}{|c|c|c|c|c|}
\hline Relevance & Year & Spring & Summer & Autumn \\
\hline Weak negative correlation & 0 & 0.02 & 16.19 & 0.56 \\
\hline Weak positive correlation & 0.06 & 5.88 & 49.11 & 58.74 \\
\hline Low degree positive correlation & 13.76 & 72.83 & 33.42 & 40.36 \\
\hline Significant positive correlation & 85.89 & 21.27 & 1.48 & 0.34 \\
\hline Extremely significant positive correlation & 0.29 & 0 & 0 & 0 \\
\hline
\end{tabular}

Table 10. Statistical table of spatial distribution of temporal variation trend of correlation between NDVI and effective precipitation in Huangshui River Basin (\%).

\begin{tabular}{|c|c|c|c|c|c|c|c|}
\hline Correlation change trends & EAP & Spring & Summer & Autumn & AVEP & MVEP & MMDEP \\
\hline Extremely significant decrease & 0 & 0 & 0.76 & 0 & 0 & 0 & 0 \\
\hline Significant decrease & 0 & 0 & 2.80 & 0 & 0 & 0 & 0 \\
\hline No significant change & 20.77 & 0.86 & 31.24 & 18.98 & 20.70 & 20.65 & 20.60 \\
\hline Significant increase & 63.63 & 1.50 & 12.82 & 16.23 & 65.00 & 70.71 & 70.43 \\
\hline Extremely significant increase & 15.60 & 97.64 & 52.38 & 64.79 & 14.3 & 8.64 & 8.97 \\
\hline
\end{tabular}


Huangshui River Basin, and the unused land is mainly distributed in Northwest (Fig. 9 a-c). From 2000 to 2018, the NDVI of arable land, forest land, grassland, water area and unused land in Huangshui River Basin showed an increasing trend, with an average annual growth rate of $0.36 \%, 0.27 \%, 0.28 \%, 0.24 \%$ and $0.17 \%$ respectively. The average decreasing rate of urban land is $0.13 \%$, and the average annual decreasing rate is $0.112 \%$ (Fig. 10 a). NDVI of forest land in spring, summer and autumn was the highest among different land use types, followed by arable land and grassland (Fig. 10 c-e). From 1980 to 2017, the natural vegetation area was $2839 \mathrm{~km}^{2}$, and the plantation area increased significantly with an average annual growth rate of $184 \mathrm{~km}^{2}$. By 2017, the artificial vegetation area increased by $3128 \mathrm{~km}^{2}$, and the total forest area reached $5967 \mathrm{~km}^{2}$ (Fig. 9 d-f). From 2000 to 2005 , the area converted from cultivated land and grassland into forest land was $77.73 \mathrm{~km}^{2}$
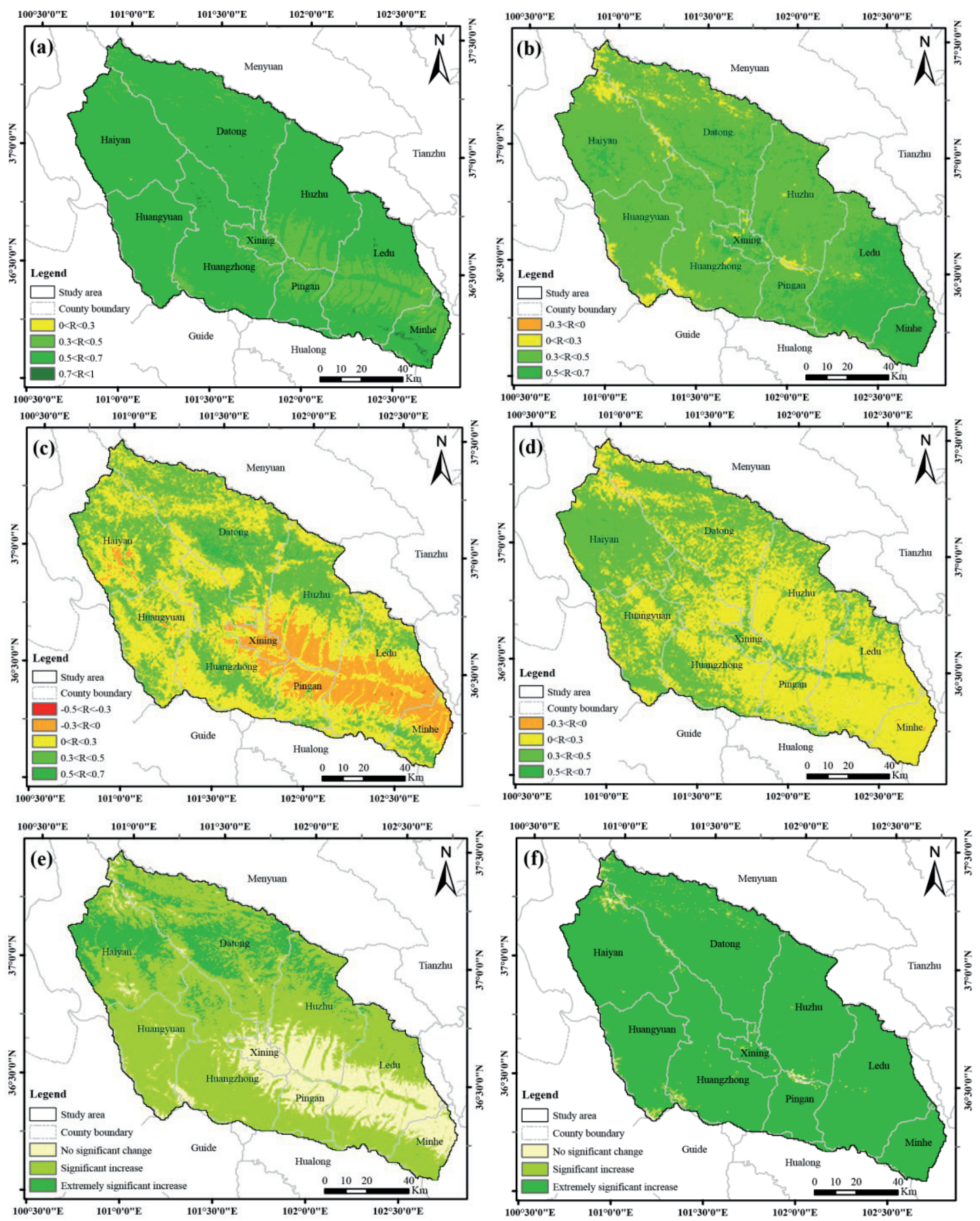

Fig. 7. Spatial distribution map of correlation between annual a), spring b), summer c), autumn d) NDVI and effective accumulated precipitation from 2000 to 2018; The spatial distribution of temporal change trend of correlation between annual e), spring f), summer g), autumn h) NDVI and EAP, and between annual NDVI and AVEP i), MVEP j) or MMDEP k). 

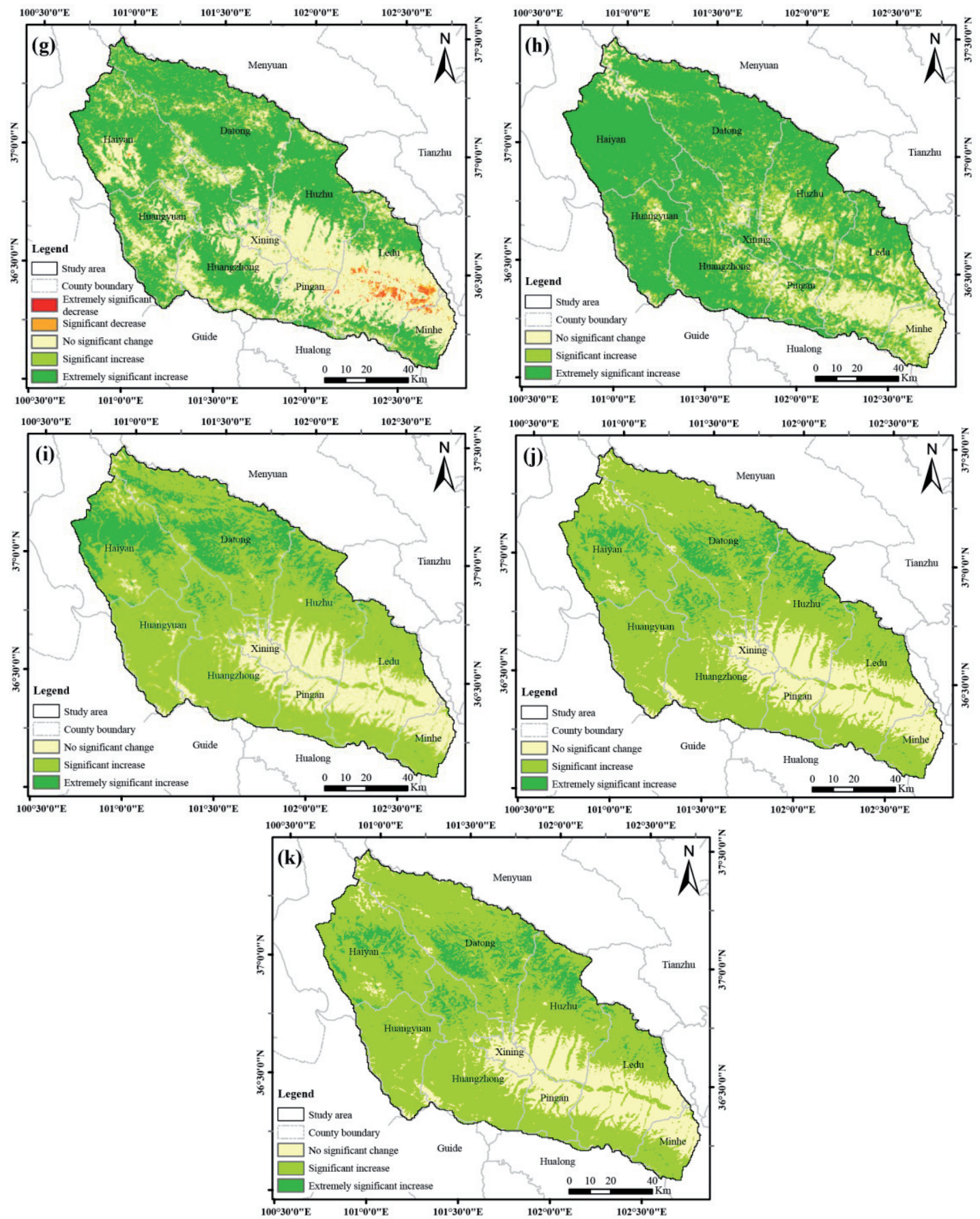

Fig. 7. Continued.

and $795.75 \mathrm{~km}^{2}$ respectively (Table 13); from 2005 to 2017, the areas converted from cultivated land, grassland and unused land into forest land were $569.14 \mathrm{~km}^{2}$, $3059.13 \mathrm{~km}^{2}$ and $76.15 \mathrm{~km}^{2}$ respectively (Table 14). Based on the analysis of landscape pattern, we can see that, In the period from 2000 to 2017, the ED and NP of land use types increased significantly, the MPS decreased significantly, the proportion of the largest patch of arable land and grassland (LPI) decreased significantly, while the LPI of forest land increased significantly (Table 15), indicating that land use change was affected by human activities.

\section{Discussion}

Analysis of the Influence of Climate Factors on NDVI

Global climate change has had a significant impact on terrestrial ecosystems. Relevant studies have shown that NDVI has a significant positive correlation with precipitation and temperature [22, 36], and the correlation between NDVI and precipitation is higher than that between NDVI and temperature [9, 11]. The results of this study also indicate that the correlation 

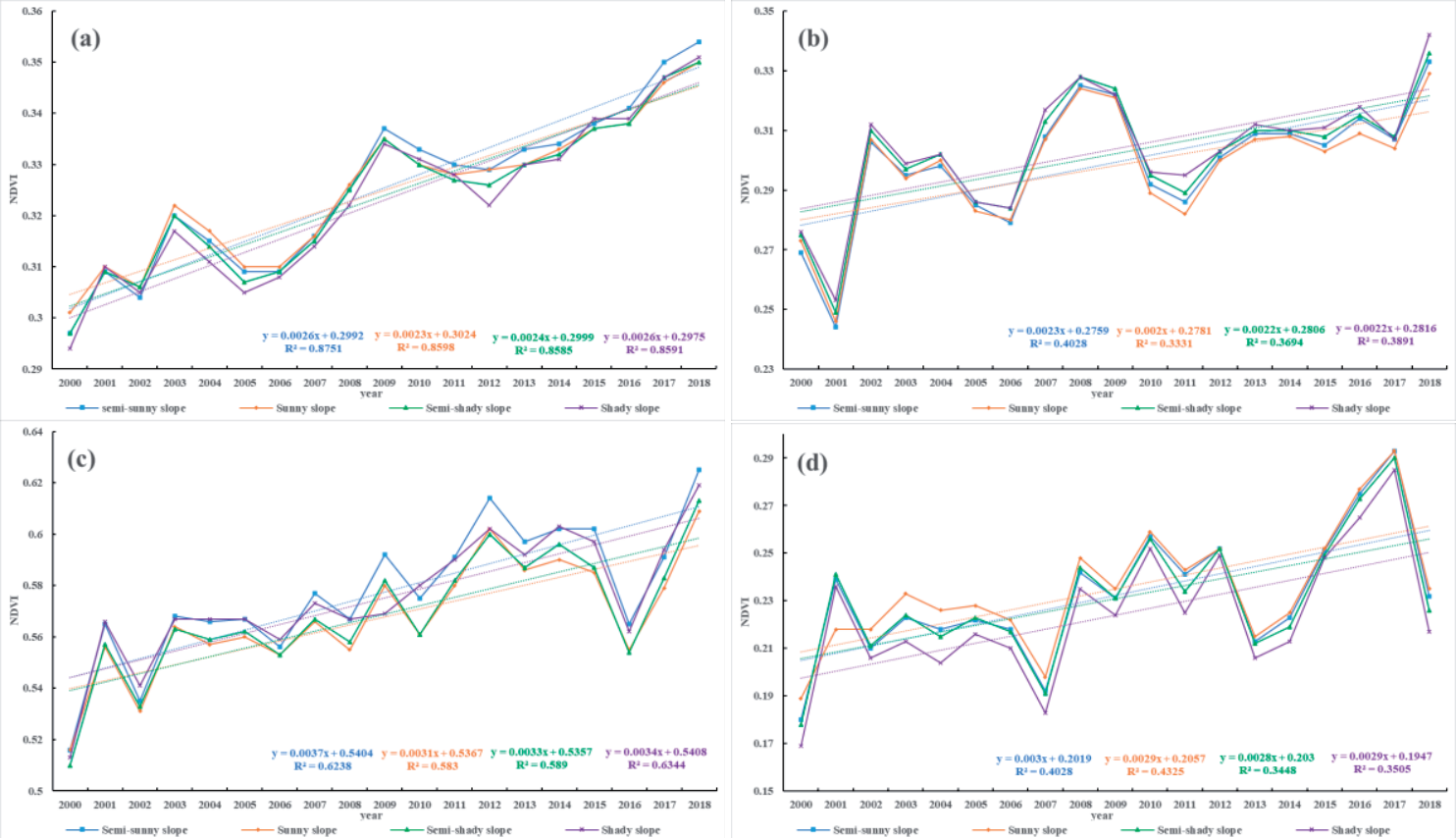

Fig. 8. The relationships between annual NDVI(a), NDVI in spring (b), summer (c), autumn (d) and slope aspect changes from 2000 to 2018.

Table 11. Statistical table of NDVI in different geomorphic units of Huangshui River Basin (\%).

\begin{tabular}{|c|c|c|c|c|}
\hline Geomorphic Units & NDVI $<0.1$ & $0.1<\mathrm{NDVI}<0.3$ & $0.3<\mathrm{NDVI}<0.5$ & NDVI $>0.5$ \\
\hline Naoshan area & 0.7 & 18.17 & 79.23 & 0.9 \\
\hline Qianshan area & 0.06 & 71.86 & 28 & 0.08 \\
\hline Chuanshui area & & 88.79 & 11.21 & \\
\hline
\end{tabular}

between NDVI and 16-days accumulated temperature, accumulated precipitation and effective accumulated precipitation in Huangshui River Basin is mainly positive, and precipitation is the dominant factor in the synergistic effect of precipitation and temperature. Different from other studies, the correlation difference between cumulative precipitation or effective cumulative precipitation and NDVI was small with both low correlations. The main reason was that the rainfall in the study area could not meet the water demand of vegetation in the growing season. Meanwhile, a large number of irrigation areas were distributed in the valley, and most water demand of vegetation can be enough through irrigation. Therefore, the correlation between cumulative precipitation or effective cumulative precipitation and NDVI was low. The correlation between NDVI and cumulative precipitation or effective cumulative precipitation in spring was lower than that between NDVI and 16-days cumulative temperature. The main reason was that a large number of irrigation areas were distributed in Huangshui River Basin, and most of the water demand of vegetation was met through irrigation. Therefore, the impact of precipitation on NDVI was relatively weak, while the temperature was not easily affected by human factors. Therefore, the correlation between temperature and NDVI was

Table 12. Statistical table of NDVI on different slope aspect of Huangshui River Basin (\%).

\begin{tabular}{|c|c|c|c|c|}
\hline Aspect & NDVI $<0.1$ & $0.1<\mathrm{NDVI}<0.3$ & $0.3<\mathrm{NDVI}<0.5$ & NDVI $>0.5$ \\
\hline Sunny slope & 0.4 & 35.14 & 64.3 & 0.16 \\
\hline Semi-sunny slope & 0.6 & 36.29 & 62.25 & 0.86 \\
\hline Shady slope & 0.9 & 37.73 & 60.25 & 1.12 \\
\hline Semi-shady slope & 0.4 & 37.8 & 61.22 & 0.58 \\
\hline
\end{tabular}


relatively large. The correlation between NDVI and cumulative precipitation and effective cumulative precipitation in spring decreases from southeast to northwest. The main reason was that spring precipitation is concentrated in the southeast region, which provides a suitable environment for vegetation growth and promotes the increase of NDVI in the southeast region [25]. In summer, the correlation between NDVI and 16day cumulative temperature, cumulative precipitation or effective cumulative precipitation was low in the middle and lower reaches of the Huangshui River Basin. The result is probably related to the poor water- holding capacity of soil in this region. The increase of summer temperature will lead to increased soil evaporation and vegetation transpiration, and reduce the effective soil water moisture for vegetation, which is not conducive to vegetation growth [11]. In autumn, the correlation between NDVI and 16-days cumulative temperature, cumulative precipitation and effective cumulative precipitation showed an increasing trend compared with in spring and summer. This maybe related with the hysteresis of NDVI response to climate change [23]. There were differences in the correlation between NDVI and 16-days cumulative temperature,
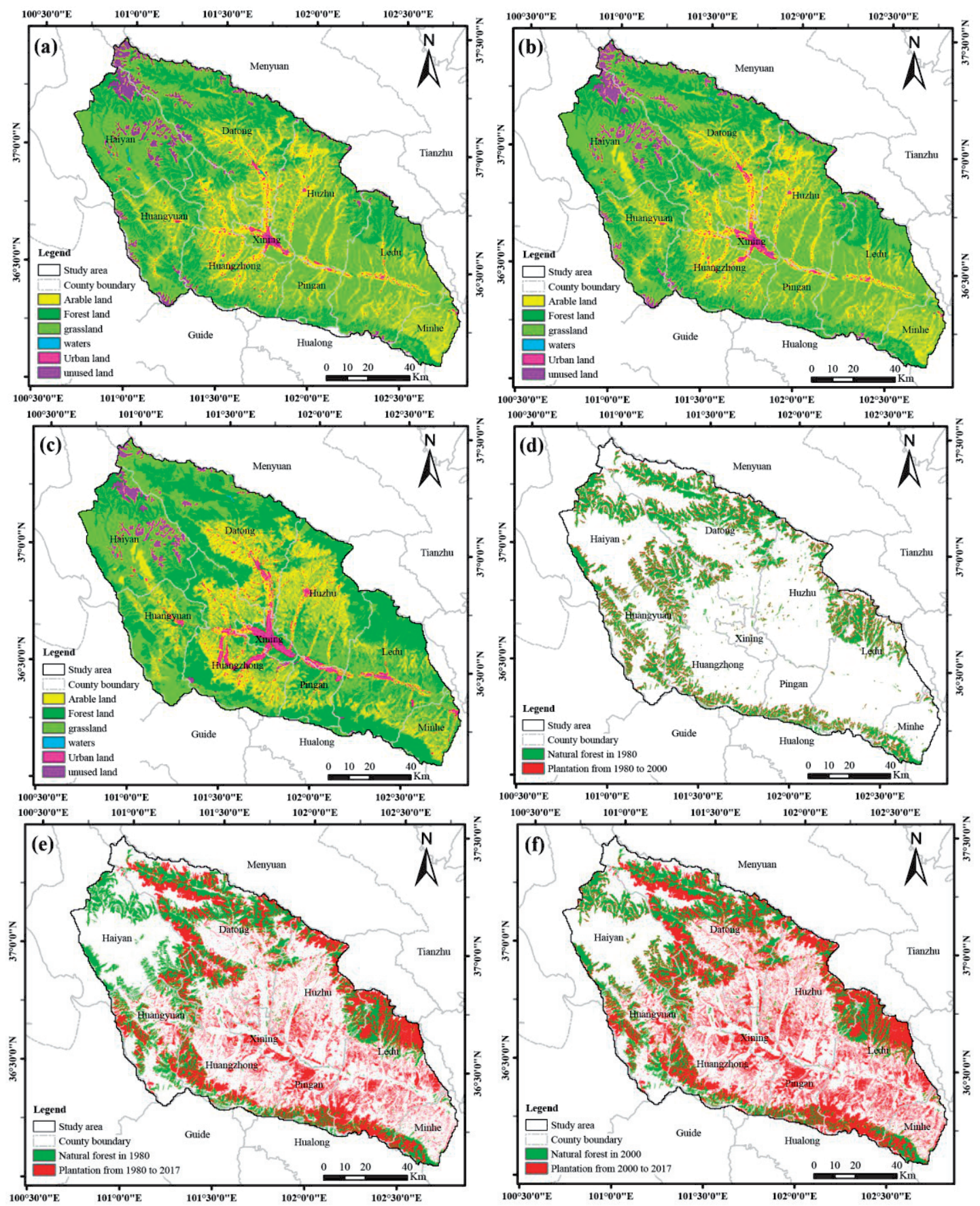

Fig. 9. The spatial distribution of land use in Huangshui River Basin in 2000 a), 2005 b), 2017 c); coupling scale of plantation and natural forest in 1980-2000 d), 1980-2017 e), 2000-2017 f). 

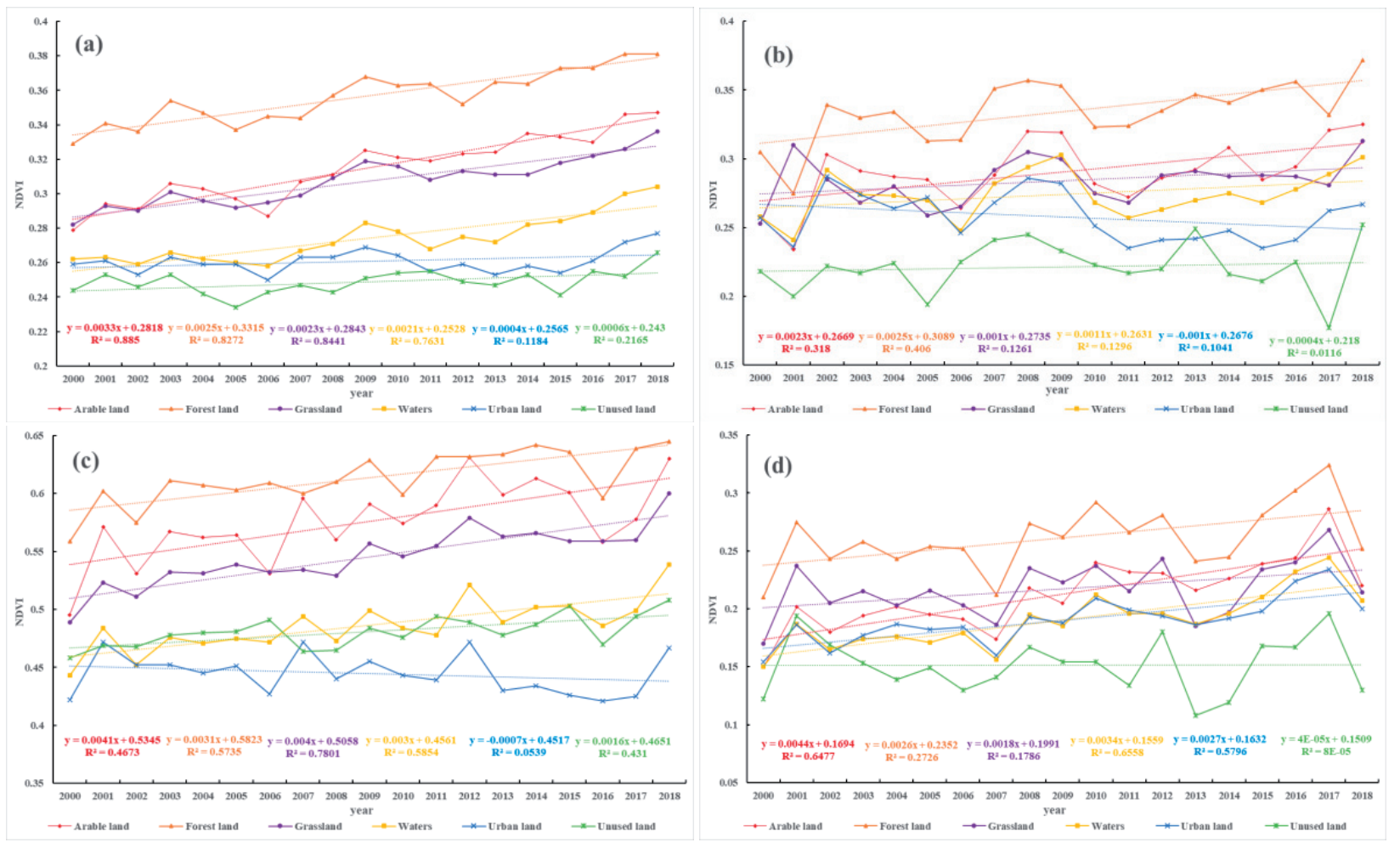

Fig. 10. The relationship between annual NDVI a), NDVI in spring b), summer c), autumn d) and land use changes from 2000 to 2018.

cumulative precipitation or effective cumulative precipitation in different seasons, which may be due to vegetation phenology [37]. The spatial variation trends of the correlation between NDVI and 16-days cumulative temperature, cumulative precipitation or effective cumulative precipitation were different. The main reason is that the Huangshui River basin is an arid and semi-arid region, and water demand of vegetation is mainly supplied by irrigation in the growing season, thus irrigation weaken the impact of precipitation on NDVI. The terrain of Huangshui River basin drops from northwest to southeast, which is favorable for the humid air entrance brought by summer wind from The Pacific Ocean, and the formation of topographic rain [38]. Due to the rising temperature, increasing snow melt water is also conducive to improving vegetation growth in highaltitude mountain areas, which promotes the increase of NDVI at high-altitude [19].

\section{Analysis of the Influence of Topography on NDVI}

Topography affects the spatial layout of NDVI by affecting the redistribution of water and heat factors [25]. Relevant studies show that in the inland mountainous areas, NDVI is high in areas with low altitude and high precipitation, and temperature is the limiting factor of NDVI in high altitude areas [18]. Some studies have also shown that the change of NDVI is closely related to human disturbance and soil moisture [20, 38]. In this paper, it is found that NDVI is not only affected by altitude and aspect, but also affected by surface conditions and human factors. The Qianshan area and Chuanshui area of Huangshui River Basin have low altitude, good water and heat conditions, but low NDVI. This mainly because the

Table 13. Statistical table of land use transfer matrix in Huangshui River Basin from 2000 to $2005\left(\mathrm{~km}^{2}\right)$.

\begin{tabular}{|c|c|c|c|c|c|c|}
\hline Type & Arable land & Forest land & Grassland & Waters & Urban land & Unused land \\
\hline Arable land & 1955.81 & 77.73 & 774.78 & 26.77 & 142.12 & 0.28 \\
\hline Forest land & 119.89 & 1900.3 & 757.21 & 4.23 & 7.65 & 10.67 \\
\hline Grassland & 812.71 & 795.74 & 6851.96 & 8.09 & 35.16 & 152.71 \\
\hline Waters & 33.68 & 1.129 & 8.746 & 15.58 & 6.62 & 0.06 \\
\hline Urban land & 103.13 & 3.03 & 45.55 & 4.04 & 138.79 & 0.1 \\
\hline Unused land & 0.24 & 14.48 & 151.21 & 0.2 & 0 & 382.33 \\
\hline
\end{tabular}


Table 14. Statistical table of land use transfer matrix in Huangshui River Basin from 2005 to $2017\left(\mathrm{~km}^{2}\right)$.

\begin{tabular}{|c|c|c|c|c|c|c|}
\hline Type & Arable land & Forest land & Grassland & Waters & Urban land & Unused land \\
\hline Arable land & 1687.08 & 569.14 & 389.37 & 25.88 & 353.48 & 6.15 \\
\hline Forest land & 72.68 & 2231.61 & 511.73 & 5.46 & 11.28 & 3.52 \\
\hline Grassland & 1664.33 & 3059.13 & 3825.59 & 10.23 & 105.37 & 52.51 \\
\hline Waters & 10.53 & 7.81 & 5.14 & 25.11 & 10.3 & 0.03 \\
\hline Urban land & 79.33 & 23.39 & 12.72 & 3.57 & 211.26 & 0.22 \\
\hline
\end{tabular}

Qianshan area is mostly covered by loess or rocky ridge, the terrain is fragmented, which is not conducive to the large-scale growth of vegetation. Chuanshui area is the main distribution area of cultivated land and urban residential construction land. The areas with high NDVI are mainly distributed above $2700 \mathrm{~m}$ above sea level, which are mainly key ecological environment governance areas. There are Datong Beichuan river source National Nature Reserve, Huangshui source ecological protection area and National Forest Park for afforestation and grass planting. A large number of soil and water conservation projects and ecological environment engineering construction projects have been carried out in Huangshui River Basin. Up to 2017, the ecological restoration area of slopes will reach $3736 \mathrm{~km}^{2}$ [28], which will reduce the impact of slope aspect on NDVI. The main reasons for the different growth rates of NDVI on different slope are different sunshine hours. On sunny slopes, long sunshine hours, which enhanced evaporation, reduced soil moisture content [39], therefore, NDVI was inhibited on sunny slope. In contrast, the semi-sun slope has a positive effect on NDVI in summer when the hydrologic and heat conditions are good. The shady slope is less affected by human disturbance with low evaporation, and the vegetation is relatively lush.

\section{Impact of Land Use Types on NDVI}

Land use change can directly reflect the surface conditions. Relevant studies show that in the pilot area of ecological restoration, the cumulative afforestation area has a significant correlation with NDVI [11]. The results show that NDVI in the middle and lower reaches

Table 15. Analysis and statistics of landscape pattern of Huangshui River Basin from 2000 to 2017.

\begin{tabular}{|c|c|c|c|c|c|c|}
\hline Type & Year & $\mathrm{CA}$ & NP & LPI & ED & MPS \\
\hline \multirow{3}{*}{ Arable land } & 2000 & 297755.3 & 444 & 5.85 & 13.84 & 670.62 \\
\hline & 2005 & 303109.8 & 459 & 5.1 & 12.43 & 660.37 \\
\hline & 2017 & 351405.3 & 18861 & 2.88 & 30.7 & 18.63 \\
\hline \multirow{3}{*}{ Forest land } & 2000 & 280014.2 & 1076 & 0.71 & 11.4 & 260.24 \\
\hline & 2005 & 283627 & 1112 & 0.66 & 10.35 & 255.06 \\
\hline & 2017 & 596723.1 & 27189 & 3.78 & 28.25 & 21.95 \\
\hline \multirow{3}{*}{ Grassland } & 2000 & 865740.2 & 526 & 17.15 & 22.87 & 1645.89 \\
\hline & 2005 & 871715.2 & 547 & 15.12 & 20.67 & 1593.62 \\
\hline & 2017 & 497407.3 & 27691 & 10.32 & 26.74 & 17.96 \\
\hline \multirow{3}{*}{ Waters } & 2000 & 6581.7 & 39 & 0.14 & 0.71 & 168.76 \\
\hline & 2005 & 5892.21 & 39 & 0.13 & 0.6 & 151.08 \\
\hline & 2017 & 7046.55 & 4269 & 0.02 & 1.6 & 1.65 \\
\hline \multirow{3}{*}{ Urban land } & 2000 & 29462.94 & 1042 & 0.18 & 1.92 & 28.28 \\
\hline & 2005 & 33049.08 & 1012 & 0.31 & 1.78 & 32.66 \\
\hline & 2017 & 69177.87 & 25311 & 1.16 & 8.93 & 2.73 \\
\hline \multirow{3}{*}{ Unused land } & 2000 & 54901.62 & 250 & 0.79 & 1.77 & 219.61 \\
\hline & 2005 & 58419.81 & 238 & 0.84 & 1.69 & 245.46 \\
\hline & 2017 & 34052.76 & 1324 & 0.34 & 1.37 & 25.72 \\
\hline
\end{tabular}


and northwest of Huangshui River Basin is increasing, which is mainly affected by human factors [1, 19]. The spatial average range of NDVI of natural forest is $0.372-0.41$, and that of plantation is $0.299-0.362$. The average annual increasing rates of NDVI of natural forest and plantation were $0.2 \%$ and $0.33 \%$ respectively. Although the NDVI of natural forest is larger than that of artificial forest, its growth rate is slow. At the same time, the increase of NDVI of plantation also benefits from the improvement of quality and efficiency of irrigation area, As of 2014, the irrigation area on the north and south sides of Huangshui River Basin was $870.6 \mathrm{~km}^{2}$, and $613.33 \mathrm{~km}^{2}$ was added in the target plan in 2020, indicating that plantation is an important factor for the increase of NDVI. Relevant studies showed that climate warming has a significant impact on cultivated land production, but the impact of human activities on cultivated land also cannot be ignored [31]. The growth rate of NDVI in cultivated land is the largest, and this change can be explained by agricultural activities, such as the use of fertilizer and pesticides, the construction of water conservation facilities, and intensive agricultural management, which led to increases in grain yields or biomass production, thus increasing the NDVI in these areas [22]. However, the NDVI of urban land shows a decreasing trend, which is mainly due to the acceleration of urbanization and urbanization process, and the continuous expansion of roads and residential land [40]. Although the vegetation quality of urban land has been improved, the large reduction of vegetation area leads to the low NDVI.

\section{Conclusions}

The main conclusions are as follows. First of all, from 2000 to 2018, the average annual increase of NDVI in Huangshui River Basin was $0.28 \%$. The NDVI in the middle and lower reaches and the northwest region of Huangshui River Basin was low, but both showed a significant increase trend. The area with significantly decreasing trend of NDVI of Huangshui River Basin was mainly distributed in the Central River Valley. Secondly, NDVI has significant correlation with accumulated temperature, accumulated precipitation and effective accumulated precipitation of 16 days in Huangshui River basin, and the areas with significant positive correlation account for $77.89 \%, 86.52 \%$ and $86.18 \%$ respectively. However, the correlation between NDVI and accumulated temperature, accumulated precipitation and effective accumulated precipitation in the middle and lower reaches of Huangshui River basin is poor and the change trend is not significant. Thirdly, The areas with high NDVI are mainly distributed in Huangshui River basin with altitude above $2700 \mathrm{~m}$. Elevation and aspect have certain influence on NDVI change, but surface condition and human factors have greater influence on NDVI distribution in Huangshui River basin. Fourth, the NDVI of woodland is the largest in Huangshui River basin, followed by cultivated land and grassland, but the growth rate of NDVI in cultivated land is the largest. The development of artificial irrigation technology and the large area increase of plantation are the important factors of NDVI increase. This paper discusses the response of NDVI to temperature, precipitation, topography and land use. In the future research, the sunshine and radiation factors in climate factors are needed to be further analyzed and the influence mechanism of topography and soil moisture on NDVI should be investigated.

\section{Acknowledgements}

This work was supported by the National Key Research and Development Project (No. 2017YFA0605004), the National Science Fund for Distinguished Young Scholars (No. 51725905), the National Key Research and Development Project (No. 2016YFA0601503), the National Science Fund for Young Scholars (No. 51709277).

\section{Conflict of Interest}

The authors declare that there are no conflicts of interest regarding the publication of this paper.

\section{References}

1. HAN J.C., HUANG Y.F., ZHANG H., WU X.F. Characterization of elevation and land cover dependent trends of NDVI variations in the Hexi region, northwest China. Journal of Environmental Management. 232, 1037, 2018.

2. ZHANG C., LU D.S., CHEN X., ZHANG Y.M., MAISUPOVA B., TAO Y. The spatiotemporal patterns of vegetation coverage and biomass of the temperate deserts in central Asia and their relationships with climate controls. Remote Sensing of Environment. 175, 271, 2016.

3. TAO J., XU T.Q., DONG J.W., YU X.Q., JIANG Y.B., ZHANG Y.J., HUANG K., ZHU J.T., DONG J.X., XU Y.M., WANG S.S. Elevation-dependent effects of climate change on vegetation greenness in the high mountains of southwest China during 1982-2013. International Journal Climatology. 11, 1002-5314, 2017.

4. LI T.Y., MENG Q.M. Forest dynamics to precipitation and temperature in the Gulf of Mexico coastal region. International Journal of Biometeorology. 61, 869, 2017.

5. BIANCHI E., VILLALBA R., SOLARTE A. NDVI Spatio-temporal Patterns and Climatic Controls Over Northern Patagonia. Ecosystems. 23, 84, 2020.

6. TONG S.Q., ZHANG J.Q., BBO Y.H., WURINA., TERIGELE., WEILIS I., LIANXIA O. Spatial and temporal variations of vegetation cover and the relationships with climate factors in Inner Mongolia based on GIMMS NDVI3g data. Journal of Arid Land. 9, 394, 2017. 
7. ZHENG Y.T., HAN J.C., HUANG Y.F., FASSNACHT S.R., XIE S., LV E.Z., CHEN M. Vegetation response to climate conditions based on NDVI simulations using stepwise cluster analysis for the Three-River Headwaters region of China. Ecological Indicators. 92, 18, 2018.

8. ZHANG Y.J., ZHAI J., MA H.P., LI Z.L., RAHAMAN M.H., DAI Y.G. Spatio-temporal variation of fractional vegetation coverage and response to climatic factors in Three Gorges Reservoir area from 2010 to 2014. Earth and Environmental Science. 94, 012126, 2017.

9. XU H.J., WANG X.P., YANG T.B. Trend shifts in satellitederived vegetation growth in Central Eurasia, 1982-2013. Science of the Total Environment. 579, 1658, 2017.

10. VANDANDORJ S., GANTSETSEG B., BOLDGIV B. Spatial and temporal variability in vegetation cover of Mongolia and its implications. Journal of Arid Land. 7 (4), 450, 2015.

11. LIU X.F., ZHU X.F., LI S.S., LIU Y.X., PAN Y.Z. Changes in Growing Season Vegetation and Their Associated Driving Forces in China during 2001-2012. Remote Sens, 7, 15517, 2015.

12. GU Z.J., DUAN X.W., SHI Y.D., LI Y., PAN X. Spatiotemporal variation in vegetation coverage and its response to climatic factors in the Red River Basin, China. Ecological Indicators. 93, 54, 2018.

13. XU Y.F., YANG J., CHEN Y.N. NDVI-based vegetation responses to climate change in an arid area of China. Theoretical and Applied Climatology. 126, 213, 2016.

14. WEN Z.F., WU S.J., CHEN J.L., LÜ M.Q. NDVI indicated long-term interannual changes in vegetation activities and their responses to climatic and anthropogenic factors in the Three Gorges Reservoir Region, China. Science of the Total Environment. 574, 947, 2017.

15. MA W.Y., WANG X.M., NA Z., JIAO L.L. Relative importance of climate factors and human activities in impacting vegetation dynamics during 2000-2015 in the Otindag Sandy Land, northern China. Journal of Arid Land. 9 (4), 558, 2017.

16. ZHAO A.Z., ZHANG A.B., LIU X.F., CAO S. Spatiotemporal changes of normalized difference vegetation index(NDVI) and response to climate extremes and ecological restoration in the Loess Plateau, China. Theoretical and Applied Climatology. 132, 555, 2018.

17. TIAN H.J., CAO C.X., CHEN W., CHEN W., BAO S.N., YANG B., MYNENI R.B. Response of vegetation activity dynamic to climatic change and ecological restoration programs in Inner Mongolia from 2000 to 2012. Ecological Engineering. 82, 276, 2015.

18. VERBYLA D., KURKOWSHI T.A. NDVI-Climate relationships in high-latitude mountains of Alaska and Yukon Territory. Arctic, Antarctic, and Alpine research. 51 (1), 397, 2019.

19. GANTSETSEG B., ISHIZUKA M., KUROSAKI Y., MIKAMI M. Topographical and hydrological effects on meso-scale vegetation in desert steppe, Mongolia. Journal of Arid Land. 9 (1), 132, 2017.

20. LIU X.F., ZHU X.F., PAN Y.Z., LI S.S., MA Y.Q., NIE J.A. Vegetation dynamics in Qinling-Daba Mountains in relation to climate factors between 2000 and 2014. Journal of Geographical Sciences. 26 (1), 45, 2016.

21. BROWNING D.M., MAYNARD J.J., KARL J.W., PETERS D.C. Breaks in MODIS time series portend vegetation change: verification using long-term data in an arid grassland ecosystem. Ecological Applications. 27 (5), 1677, 2017.
22. NING T.T., LIU W.Z., LIN W., SONG X.Q. NDVI Variation and Its Responses to Climate Change on the Northern Loess Plateau of China from 1998 to 2012. Advances in Meteorology. 1, 1, 2015.

23. GUAN Q.Y., YANG L.Q., GUAN W.Q., WANG F.F., LIU Z.Y., XU C.Q. Assessing vegetation response to climatic variations and human activities: spatiotemporal NDVI variations in the Hexi Corridor and surrounding areas from 2000 to 2010. Theoretical and Applied Climatology. 135, 1179, 2019.

24. LIU Y.X., WANG Y.L., DU Y.Y., ZHAO M.Y. PENG J. The application of polynomial analyses to detect global vegetation dynamics during 1982-2012. International Journal of Remote Sensing. 37 (7), 1568, 2016.

25. LIU Q., YANG Z.P., HAN F., WANG Z.G., WANG G.R. NDVI-based vegetation dynamics and their response to recent climate change: a case study in the Tianshan Mountains, China. Environmental earth sciences. 75, 1189, 2016.

26. SUN W.Y., SONG X.Y., MU X.M., GAO P., WANG F., ZHAO G.J. Spatiotemporal vegetation cover variations associated with climate change and ecological restoration in the Loess Plateau. Agricultural and Forest Meteorology. 15, 209, 2015.

27. CHENG C.X., WANG Z.H., XIAO Z.X., XU Z.X., JIAO P., DONG G.T., WEI G.J. Spatio-temporal dynamics of NDVI and its response to climate factors in the Heihe River Basin, China. Earth and Environmental Science. 82, 012045, 2017.

28. HE S., QIN T.L., LIU F., LIU S.S., DONG B.Q., WANG J.W., NIE H.J. Effects of Slope Ecological Restoration on Runoff and Its Response to Climate Change. Environmental Research and Public Health. 16, 4017, 2019.

29. LIU F., QIN T.L., YAN D.H., WANG Y., DONG B.Q., WANG J.W., NIE H.J., HE S., LIU S.S. Classification of Instream Ecological Water Demand and Crucial Values in a Semi-arid River Basin. Science of the Total Environment. 712, 136409, 2020.

30. LI C.L., FILHO W.L., WANG J., YIN J., FEDORUK M., BAO G., BAO Y.H., YIN S., YU S., HU R.C. An assessment of the impacts of climate extremes on the vegetation in Mongolian Plateau: Using a scenarios-based analysis to support regional adaptation and mitigation options. Ecological Indicators. 95, 805, 2018.

31. XIONG Q.L., XIAO Y., HALMY W.A., DAKHIL M.A., LIANG P.H., LIU C.G., ZHANG L., PANDEY B., PAN K., KAFRAWAY S.B.E., CHEN J. Monitoring the impact of climate change and human activities on grassland vegetation dynamics in the northeastern Qinghai-Tibet Plateauof China during 2000-2015. Journal of Arid Land. 11 (5), 637, 2019.

32. WANG T., YANG M.H., YAN S.J., GENG G.P., LI Q.H.. WANG F. Temporal and Spatial Vegetation Index Variability and Response to Temperature and Precipitation in the Qinghai-Tibet Plateau Using GIMMS NDVI. polish journal of environmental studies. 29 (6), 4385, 2020.

33. NIE H.J., QIN T.L., LI C.Z., TANG Y., WENG B.S., WANG Y. Trend analysis of effective precipitation in different growth stages of winter wheat in Huaihe River Plain. Theoretical and Applied Climatology. 138, 2043, 2019.

34. ZHANG J.Y., ZHANG S.C. The analysis and research of integrated irrigation quota in huangshui river basin. Yellow River. 12, 41, 1997.

35. LIU F., QIN T.L., GIRMA A., WANG H., WENG B.S., YU Z.L., WANG Z.L. Dynamics of Land-Use and Vegetation 
Change Using NDVI and Transfer Matrix: A Case Study of the Huaihe River Basin. polish journal of environmental studies. 213, 2019.

36. DU J.Q., HE P., FANG S.F., LIU W.L., YUAN X.J., YIN J.Q. Autumn NDVI contributes more and more to vegetation improvement in the growing season across the Tibetan Plateau. International Journal of Digital Earth. 1753, 2017.

37. XIE B.N., JIA X.X., QIN Z.F., SHEN J., CHANG Q.R. Vegetation dynamics and climate change on the Loess Plateau, China: 1982-2011. Regional Environmental Change. 16, 1583, 2016.

38. XUE F., ZENG Q.C., HUANG R.H., LI C.Y., LU R.Y. ZHOU T.J. Recent Advances in Monsoon Studies in China. Advances in Atmospheric Sciences. 32 (02), 206, 2015.
39. ZHANG Y.W., DENG L., YAN W.M., SHANGGUAN Z.P. Interaction of soil water storage dynamics and long-term natural vegetation succession on the Loess Plateau, China. Catena. 137, 52, 2016.

40. WANG H.S., LIU D.S., LIN H., MONTENGRO A. ZHU X.L. NDVI and vegetation phenology dynamics under the influence of sunshine duration on the Tibetan plateau. International Journal of Climatology. 35 (5), 687, 2015.

41. YANG X.M., LIU S.Z., YANG T.B., XU X.Y., KANG C.Z., TANG J.N., WEI H.D., GHEBREZGABHER M.G., LI Z.Q. Spatial-temporal dynamics of desert vegetation and its responses to climatic variations over the last three decades: a case study of Hexi region in Northwest China. journal of arid land. 8 (4), 556, 2016. 
